\title{
Incidencia de la Iglesia Luterana en las migraciones y el desplazamiento forzoso
}

\author{
Incidence of the Lutheran Church in migrations \\ and forced movements
}

\author{
Blanca Irma Rodríguez \\ coordinadora Pastoral del Migrante \\ Sínodo Luterano Salvadoreño \\ blancairmas@gmail.com
}

Recibido: 30/10/2015 - Aprobado: 30/11/2015

\section{Resumen}

Este artículo expone el trabajo de la ILS en el tema migratorio, pero además analiza el fenómeno de la migración desde sus orígenes hasta su repercusión en el desarrollo de El Salvador; y sostiene que las migraciones se producen diferentes repuntes debido a los múltiples fenómenos naturales que provocan tragedias por el alto nivel de vulnerabilidad de la población. Unas veces son provocados por terremotos, otras por temporales o por las sequías. Pero en los últimos años lo que ha elevado el número de migraciones es el alto índice de violencia. Muchas familias se ven afectadas de diversas maneras, y la única forma que encuentran para salvaguardar su vida y la de sus seres queridos es huir del país.

\section{Palabras clave}

Migración, Iglesia Luterana, violencia.

\section{Abstract}

This article shows the work of the Salvadorean Lutheran Church (ILS, given its Spanish acronym) in the topic of migration ; it also analyzes the phenomenon of migration from its roots to its incidence in the development of El Salvador.

It maintains that migrations take place in different surges due to distinct natural phenomena that cause tragedies as a result of the population's high level of vulnerability. Sometimes these are triggered by earthquakes, others by floods or droughts. In the past few years, though, what increased the number of migrations is the high level of violence. A number of families are affected in a variety of ways and the only manner in which they find how to safeguard their lives and that of their loved ones is by fleeing the country.

\section{Keywords}

Migration, Lutheran Church, violence.

1 Licenciada en Trabajo Social y en Teología, ordenada Presbítera de la Iglesia Luterana Salvadoreña, posee una maestría en Teología en el área de Teología e Historia por el Instituto de Pós Graduação de São Leopoldo RS/Brasil. Coordinadora del Centro de Investigaciones y docente a tiempo completo de la Universidad Luterana Salvadoreña, coordinadora Pastoral del Migrante Sínodo Luterano Salvadoreño. 


\section{Antecedentes}

La Iglesia Luterana Salvadoreña nace con un pequeño grupo "retornados", tal como se conocen ahora. En aquel tiempo se identificaban como deportados. Esto sucedió en 1969 cuando se libró la guerra de las 100 horas entre El Salvador y Honduras. Un grupo de salvadoreños entraron al país por el departamento de La Unión y llegaron a Pasaquina, donde se encontraba el pastor Mauro Recinos y su esposa Blanca Marina Méndez.

Al ver la situación de calamidad en la que llegaban los hermanos, que venían huyendo de los atropellos de las autoridades hondureñas para expropiarles sus pertenencias, decidieron hacer un trabajo social y pastoral con ellos. Para eso solicitaron ayuda a organismos extranjeros como Pan para el Mundo, con ese apoyo se compró un terreno para construir algunas viviendas y el resto fue utilizado para que las familias hicieran sus cultivos.

En los años 80 se dio otro auge migratorio provocado por la guerra civil que duró más de una década. Este grueso flujo de gente desplazándose a la ciudad sobrepasó la capacidad de las instituciones humanitarias de ayuda y demandó que instituciones como la Iglesia Luterana, tomara parte en la atención a la población que estaba siendo desplazada por los intensos bombardeos en las faldas del volcán Chichontepec, en el departamento de San Vicente. Este flujo de personas de mantuvo tanto internamente como hacia el extranjero.

En lo que va de la presente década las migraciones continúan en aumento a causa de la violencia de pandillas, que ha tomado auge en los últimos años. La Iglesia como institución también se ha visto afectada por esta violencia. El 4 de noviembre de 2006, una pareja de esposos, pastores, fueron asesinados en la colonia 15 de Septiembre, en la comunidad luterana "Montes de Pensberg", en la jurisdicción de Jayaque, departamento de La Libertad. La violencia continúa en aumento y los daños causados a las familias, también.

\section{El Salvador: origen y destino de flujos migratorios}

El año 2000 en El Salvador se convierte en uno que marca un nuevo período de incremento migratorio. Muchas personas salen hacia otros países, principalmente a los Estados Unidos de Norteamérica. Por otro lado, el país también se ha convertido en receptor de significativos flujos migratorios laborales, especialmente de la región centroamericana, en las temporadas de las cortas de café y de la zafra, entre los que destaca población hondureña y nicaragüense, que llega atraída por los beneficios que le deja, en su país de origen, el hecho de devengar su salario en dólares.

Por otra parte, El Salvador también se ha convertido en una vía de tránsito para los flujos migratorios continentales y extracontinentales. Como Iglesia Luterana, se ha tenido la necesidad de apoyar a migrantes que han llegado al país en tránsito hacia el Norte procedentes de diferentes países y continentes. La Iglesia cuenta con una casa de huéspedes, donde ha tenido la oportunidad de acoger a migrantes refugiados de Sri Lanka, Kenia, Argelia e inclusive un hombre de Eritrea; y de Sur América, a un grupo de colombianos. Este trabajo se hace en coordinación con Acnur y la Iglesia Anglicana. Todos ellos llegaron al país utilizándolo como puente en su ruta hacia los Estados Unidos de Norteamérica.

La denominada crisis humanitaria surge "del Gobierno estadounidense en camino a convertir a los menores migrantes en seres innombrables e inclasificables a los que no hay ley o derecho nacional o internacional que los proteja". ${ }^{2}$ La niñez y los adolescentes no migran, están huyendo de la violencia generalizada en el país; ellos son los más vulnerables porque las pandillas reclutan a niños y niñas de todas las edades, según sea el objetivo para el que los quieren utilizar.

Por otro lado, los adultos también migran por diferentes circunstancias; además de la violencia, también por la necesidad de mejorar sus condiciones de vida debido a la falta de oportunidades, lo cual va más allá de nuestras fronteras, convirtiéndose en un clamor generalizado, demandando mejoras de las condiciones de vida de los países del Sur.

2 http://www.contrapunto.com.sv/reportajes/crisis-humanitaria-via-libre-para-violar-los-derechos-humanos-de-la-ninez 
Esta situación de los migrantes ha demandado la atención de todas las instituciones que tengan un llamado a paliar la necesidad, pero más que eso el compromiso de buscar soluciones o alternativas de solución a este fenómeno que va en aumento. Es un servicio con amor y responsabilidad, a partir del llamado evangélico de proteger al extranjero, al migrante, y más cuando los migrantes son nuestros paisanos, nuestros vecinos, nuestra familia sanguínea y fraterna en la fe.

Hasta la fecha, la mayoría de los retornados vienen vía terrestre de la frontera de México/Estados Unidos, en buses con matrícula mexicana contratados exclusivamente para el traslado de los migrantes, los cuales entran por la frontera de Las Chinamas, y en término de dos y media a tres horas van llegando uno a uno en el transcurso de la mañana a las instalaciones de la DGME, ubicada ahora temporalmente en la colonia Utila, en Santa Tecla, departamento de La Libertad.

En la DGME ya está todo preparado para la recepción, hay personal técnico especializado que los recibe $y$ atiende en las diferentes áreas: salud, alimentación, psicosocial; asistencia legal, para quienes necesiten hacer las respectivas denuncias en el caso de haber sufrido violaciones a sus derechos humanos.

Los diferentes medios de comunicación, nacionales e internacionales, mucho han hablado de NNA no acompañados, pero lo que refleja la realidad de los retornados hasta ahora atendidos es que la mayoría de Ios NNA viajan acompañados por lo menos de un familiar, ya sea la madre, el padre, la hermana, tía, etc. Según las informaciones obtenidas, se dice que posteriormente vendrán los deportados desde los Estados Unidos, quienes llegarán al aeropuerto internacional "Monseñor Óscar Arnulfo Romero", en Comalapa, en el departamento de La Paz.

\section{La Iglesia en la emergencia de la crisis humanitaria}

La Iglesia Luterana Salvadoreña, por medio de la Pastoral del Migrante, en la emergencia de la crisis humanitaria desarrolló un trabajo de atención a NNA retornados de la ruta del migrante, principalmente de la frontera de
México/Estados Unidos. Este apoyo fue posible gracias a la cooperación del LWR[1].

El equipo de atención de la ILS estuvo presente en las instalaciones de la Dirección General de Migración y Extranjería, ubicadas en La Chacra, los meses de septiembre y octubre del 2014, con el fin de estar presente a la llegada de los buses procedentes de la frontera mexicana y hacer entrega de los respectivos paquetes de víveres a los NNA retornados, acompañados y no acompañados. El trabajo se coordinó con una red integrada por iglesias e instituciones del Estado y organizaciones no gubernamentales como: Isna, Conna, DGMR, Idhuca, Insami, Fespad, Cáritas El Salvador, Tutela Legal, Cruz Roja, Save \& Children, Plan Internacional, Acnur, Utec y Comigrantes.

Al lugar también asistió, en alguna ocasión, el obispo Medardo Gómez para conocer de primera mano el proceso de recepción de las personas retornadas y el procedimiento de entrega de los víveres. Cada paquete contiene productos de la canasta básica para paliar sus necesidades alimenticias inmediatas, calculado para sostener a una familia de cinco miembros durante un mes, tiempo en el que se espera que puedan retomar sus actividades normales e incorporarse de nuevo a las actividades productivas.

De acuerdo con las informaciones recabadas, la mayoría de los NNA retornados viajaban acompañados de alguno de sus familiares. Según sus propios testimonios, la condición de "solos o no acompañados" la asumen una vez que son interceptados por las autoridades migratorias y llevados a los centros de albergue, debido a que a los menores de edad los separan de los adultos y permanecen así hasta que son retornados, o hasta que sus familiares en Estados Unidos puedan arreglar la situación pagando la respectiva fianza.

\section{La Iglesia Luterana y las comunidades de fe, vida y sanación}

Las comunidades de fe, vida y sanación de la ILS, en su mayoría se localizan en el área rural y en zonas vulnerables, son gente de escasos recursos que viven de su salario. Muchas de estas personas están sin un empleo fijo y se dedican al sector informal de la economía. En estas comunidades, desde hace 
muchos años, la Iglesia ha venido realizando proyectos de desarrollo comunitario para apoyar a las familias.

Algunos de los proyectos son, por ejemplo, los siguientes: seguridad alimentaria, con el que se apoyan pequeños proyectos agrícolas, se les da semilla, asistencia técnica en sistemas de crédito y microcréditos; "Pan Nuestro de cada Día", dirigido a jóvenes emprendedores, proporcionándoles formación vocacional; a cada participante se le entrega un juego de herramientas de trabajo, para que pueda instalar y desarrollar su negocio; campañas médicas: se realizan dos de salud integral por año, una al inicio y la otra a mediados del año. Estas campañas son apoyadas por el Sínodo de Milwaukee, de los Estados Unidos, y se da una cobertura a unas 1.500 personas, que son atendidas en cada campaña; el Programa de Becas, con apoyo a la niñez y juventud, desde la preparatoria hasta la formación universitaria; se han entregado más de 2.500 becas.

En la organización comunitaria se hace trabajo para la reducción del riesgo, mediante la construcción de bordas en ríos que rebasan sus cauces con las fuertes lluvias y por eso amenazan la vida en las comunidades. En lo que va del año 2015, se ha hecho trabajo con el tema de migrantes en las diferentes comunidades del país, se han organizado comités locales tomando en cuenta que son ellos quienes mejor conocen la comunidad, de manera que entre ellos identifiquen a las personas retornadas y puedan tener un acercamiento a ellas.

Se ha realizado bastante trabajo con ellos, y se ha podido comprobar que en las comunidades luteranas no hay muchas personas retornadas. Este hecho puede atribuirse a dos razones: a que las personas que deciden irse ya tomaron su decisión y no van a desistir hasta lograrlo. Para ello, aprovechan las dos o tres posibilidades que el coyote ${ }^{3}$ les da para que puedan cruzar la frontera; y a que, gracias a la labor permanente que la Iglesia desarrolla en las comunidades, como comités locales, se ha hecho trabajo educativo y de concientización de los riesgos que sufre la persona en el trayecto migratorio.

También se han desarrollado proyectos de emprendedores, encaminados a dar oportunidades especialmente a las y los jóvenes, para que tengan oportunidades de desarrollar sus potencialidades y capacidades en tareas emprendedoras que contribuyan a su desarrollo personal y familiar.

En el 2014, con la ampliamente difundida crisis humanitaria por los medios de comunicación, nunca se recibió la gran cantidad de NNA retornados como están llegando ahora en el 2015. En los buses procedentes de México están llegando hasta un promedio de 80 y 100 NNA en un solo día. Y ahora los medios de comunicación, y ninguna otra institución, se pronuncia o denuncia lo que está sucediendo.

\section{La violencia como la principal causa de migración}

Las migraciones tienen diferentes repuntes debido a los múltiples fenómenos naturales que provocan tragedias por el alto nivel de vulnerabilidad de la población. Unas veces son provocados por terremotos, otras por temporales o por las sequías. Pero en los últimos años lo que ha elevado el número de migraciones es el alto índice de violencia. Muchas familias se ven afectadas de diversas maneras, y la única forma que encuentran para salvaguardar su vida y la de sus seres queridos es huir del país.

Por la falta de registros adecuados de salida no se cuenta con datos precisos, solo se tienen las cifras de retorno proporcionados por la DGMR. Según esta, el total de personas retornadas durante el año 2013 fue de 36.147, de las cuales 21.887 llegaron vía aérea y 14.260 terrestre.

La reunificación familiar y los niveles de pobreza son causas suficientes para que la gente tome la decisión de migrar. Sin embargo, en los últimos años, esta no es la causa principal. La violencia ha cobrado mayor importancia y es la causa de más desesperación en la gente, que huye buscando un lugar seguro para sobrevivir. Muchos se van por amenazas a ellos o a algún miembro de su familia, y otros por miedo a la violencia porque ya no se puede circular libremente entre las colonias y los barrios, debido a que las maras han marcado como propios ciertos territorios.

Un pequeño sondeo, realizado a través del Cuerpo Pastoral y de los Comités Locales de Migrantes, nos ha revelado que la problemática de la migración no ha afectado en mayor

3 Coyote es la persona, hombre o mujer, que se dedica a llevar personas hacia los Estados Unidos por cuantiosas sumas de dinero. 
escala las comunidades luteranas, ya que con el proyecto de migrantes hemos llegado a todas las comunidades y son pocas las personas que se han encontrado en condición de retornadas.

Sin embargo, a partir de este año 2015 , se ha detectado que el mayor problema que ha golpeado a estas comunidades es el desplazamiento forzado a causa de la violencia. Parte del equipo pastoral mismo está siendo afectado.

\section{Testimonio}

Presentamos el siguiente testimonio, en anónimo para proteger la identidad de la persona.

En el mes de agosto del 2014, hombres fuertemente armados llegaron a la casa y nos dijeron que teníamos que unirnos a ellos o, si no lo hacíamos, nos iban a matar. Ellos eran pandilleros, por eso no queríamos. Nos negamos rotundamente, diciéndoles que nosotros queríamos trabajar duro y no andar en malos pasos, por lo que se enfadaron y nos dijeron que nos arrepentiríamos.

El primero de noviembre de ese mismo año, mientras andábamos enflorando en el cementerio, llegaron al lugar en una camioneta con vidrios polarizados, y mientras nosotros estábamos en el cementerio, ellos le prendieron fuego a la casa hasta incendiarla; y nos dejaron dicho con los vecinos que nos iban a matar. Fue por miedo a que nos mataran que tuvimos que huir, pero no quisimos irnos lejos, nos quedamos en un lugar cerca donde una familiar, viviendo con ellos todos amontonados.

Después de un tiempo, las pandillas nos descubrieron y siguieron insistiendo en que nos uniéramos a ellos, pero no lo consiguieron, porque nosotros no queremos eso, preferimos trabajar y ganarnos la vida honradamente. Esto les enojó todavía más, y aumentaron las amenazas. Fue entonces que nos decidimos y tuvimos que huir para el monte y anduvimos escondiéndonos como tres meses.

Después de este tiempo, buscamos apoyo en la Iglesia Luterana y fuimos acogidos en la casa de huéspedes unos pocos días, allí nos daban techo y comida. Estuvimos allí como una semana. Después de allí nos fuimos para Sonsonate; pensamos que podíamos vivir allá con un tío, pero había muchos pandilleros y al vernos nos dijeron que no nos querían ver allí. Así que nos vimos en la necesidad de regresar a nuestro lugar de residencia.

Viendo que no nos podíamos quedar allí, y que ya no sabíamos qué hacer, buscamos apoyo en un amigo que en esos días se iba de mojado para los Estados Unidos. Así que nos decidimos y nos fuimos con él... a la voluntad de Dios.

\section{Siglas y acrónimos}

NNA niños, niñas y adolescentes

Isna Instituto Salvadoreño para la Niñez y la Adolescencia Conna Consejo Nacional de la Niñez y la Adolescencia DGMR Dirección General de Migración y Extranjería Idhuca Instituto de Derechos Humanos de la Universidad Centroamericana "José Simeón Cañas" Insami Instituto Salvadoreño del Migrante Fespad Fundación de Estudio para la Aplicación del Derecho Acnur Alto Comisionado de las Naciones Unidas para los Refugiados

Utec Universidad Tecnológica de El Salvador ILS Iglesia Luterana Salvadoreña LWR Servicio Luterano Mundial

\section{Referencias}

Declaración Universal de los Derechos Humanos de las Naciones Unidas

Informe sobre Desarrollo Humano El Salvador 2013

Programa de las Naciones Unidas para el Desarrollo (PNUD) Pastoral del migrante del SLS

Contexto y Análisis de Migración de Niños, Niñas de la Federación Luterana Mundial

Memoria Anual de Labores de la ILS, 2011

Memoria Anual de Labores de la ILS, 2012

Memoria Anual de Labores de la ILS, 2013

Memoria Anual de Labores de la ILS, 2014 